\title{
Variability of near-surface soil temperature on sagebrush rangeland
}

FREDERICK B. PIERSON AND J. ROSS WIGHT

\begin{abstract}
Models used to simulate plant growth and insect development on rangelands often assume that soil temperature is homogeneous over the entire area of interest. This simplifying assumption is made because few data are available on the magnitude and structure of the spatial variability of soil temperature within rangeland communities. The influence of sagebrush on the spatial variability and diumal fuctuations of near-surface soil temperature was examined within a sagebrush-grass plant community. Hourly soil temperatures were measured at 1-, 5-, and $10-\mathrm{cm}$ depths at $30-\mathrm{cm}$ intervals along a 12.3-m north-south transect over a 6-day period in March, 1989. Both classical and geostatistical techniques were used to quantify and model the magnitude and structure of the spatial and temporal variability. Maximum soil temperatures at the $1-\mathrm{cm}$ depth varied from 7 to $23^{\circ} \mathrm{C}$ under sagebrush and bare interspace, respectively. Periodic spatial patterns in soil temperature were found for all measured depths with a wavelength of periodicity approximately equal to the separation distance between sagebrush plants along the transect. Diurnal variability in near surface soil temperature was much greater in interspace areas compared to under sagebrush plants. The amplitude of diurnal variability in soil temperature at the $1-\mathrm{cm}$ depth under sagebrush was similar to the amplitude of the diurnal variability at the $10-\mathrm{cm}$ depth within the interspaces.
\end{abstract}

Key Words: soil temperature, spatial variability, temporal variability, sagebrush, geostatistics, semivariogram

Rangeland models are often used to simulate processes over large areas assuming related properties are homogeneous over the entire area. This assumption can lead to large errors in simulated values. For example, calculations of the soil energy balance used for prediction of such processes as plant and insect growth and evapotranspiration are strongly dependent on the measurement of soil temperature. However, soil temperature is a function of many soil, vegetation, and atmospheric variables which vary in space. Therefore, the accuracy of estimates of these physical processes may depend on a prior knowledge of the magnitude and structure of the spatial variability of soil temperature within particular plant communities.

Due to the intensive effort required to continuously monitor soil environmental variables, data on the variability of soil water and temperature on rangelands are practically nonexistent. One exception is the work done by Evans et al. (1975). Computer technology in the form of data loggers now allows continuous monitoring of soil water and temperature at various soil depths. Extensive data sets can be collected to describe spatial and temporal variations in soil water and temperatue on rangelands. These data sets can also be quite useful in soil water-temperature model development and validation.

In recent years, researchers have used geostatistical techniques to describe the variability of soil physical properties (Burgess and Webster 1980, Gajem et al. 1981, Vauclin et al. 1982, Yates and Warrick 1987, Davidoff and Selim 1988), chemical properties

\footnotetext{
Authors are research hydrologist and range scientist, respectively; USDA-ARS, Northwest Watershed Research Center, 800 Park Boulevard, Plaza IV, Suite 105, Boise, Idaho 83712.

Manuscript accepted 19 November 1990.
}

(Yost et al. 1982), hydraulic properties (Achouri and Gifford 1984, Merzougui and Gifford 1987, Hatfield et al. 1982, Hatfield et al. 1984, Russo and Bresler 1981, Sisson and Wierenga 1981, Vieira et al. 1983), nutrient status (Folorunso and Rolston 1984, Webster and Nortcliff 1984), and crop production (Williams et al. 1987, Nancy et al. 1988). Geostatistics can help quantify the magnitude of spatial variability of selected properties, as well as model the spatial structure of the variability. This kind of information can be used in a modeling framework to increase the accuracy of model estimates by dissecting the landscape into distinct units which can be modeled separately. Spatial variability information can also be used in experimental design to determine plot spacing so that classical statistical analyses can be applied without violating basic assumptions. Experimental plots must be set far enough apart so the variables of interest within each plot are not spatially correlated.

The objectives of this paper were to: (1) quantify the spatial and temporal variability of soil temperature at 3 depths under an undisturbed sagebrush-grass plant community; and (2) correlate the spatial and temporal patterns in soil temperature with the spatial distribution pattern of the litter and vegetation.

\section{Materials and Methods}

\section{Study Area}

The study area was located at the Quonset site on the Reynolds Creek Experimental Watershed in southwest Idaho. The watershed is representative of much of the rangeland found throughout the Northwest. Soils are the Larimer series (fine loamy over sandy or sandy skeletal, mixed, mesic, Xerollic Haplargids), and the vegetation is primarily big sagebrush (Artemisia tridentata tridentata) with an understory of sandberg bluegrass (Poa sandbergii) and cheatgrass (Bromus tectorum) (Stephenson 1977).

\section{Data Collection}

Soil temperature was measured with thermocouple sensors (24 gauge chromel and constantan wire) connected to Campbell Scientific CR-10 dataloggers (no endorsement implied herein). Small holes ( $4 \mathrm{~cm}$ in diameter) were drilled at $30-\mathrm{cm}$ increments along a 12.3-m north-south transect using a standard drill and wood auger. Sensors were placed in 42 locations at each of 1-, 5-, and 10-cm depths for a total of 126 soil temperature sensors. Temperature readings were made at 10 -min intervals and average hourly values were recorded for each location. Daily maximum and minimum values for each location were also determined using the 10-min readings. Soil temperatures were measured for a 6-day period from day 81 (March 22) through day 86 (March 27), 1989.

Care was taken to minimize disturbance of the soil surface and to replace all litter and vegetation after installing the sensors. Depth of litter on the surface was measured at each location to the nearest $0.5 \mathrm{~cm}$ and each location was classified as being shaded or unshaded by sagebrush plants.

\section{Statistical Analysis}

Statistical analysis of the data included computation of the sample mean, variance and coefficient of variation for maximum and minimum soil temperatures measured at each depth. The Wilk-Shapiro test for normality (Shapiro and Francia 1972) was also run for maximum and minimum temperatures at each depth.

$A$ one-way analysis of variance and a protected LSD test were 
used to test for significant differences in maximum and minimum soil temperatures between shaded and unshaded areas. Linear regression analysis was used to identify significant correlations between maximum and minimum soil temperatures and shaded or unshaded areas.

\section{Geostatistical Analysis}

Geostatistics are based on the theory of regionalized variables and were developed to determine the location of high-grade mineral ores in mining (Journel and Huijbregts 1978). Recently, geostatistics has been used in other fields such as soil science and hydrology to quantify the spatial varibility of numerous properties. Webster (1985) and Vieira et al. (1983) provide very good summaries of geostatistical theory as it applies to various aspects of soil science. They provide examples of geostatistical methods and programs for computer analysis. In addition, Isaaks and Srivastava (1989) have written a very understandable text book on the applications of basic geostatistics. The following is a summary of geostatistical theory needed for analysis of data presented in this paper.

Regionalized variable theory takes the differences between pairs of values of a property separated by a known quantity, usually distance, and expresses this as a variance. Therefore, geostatistics takes into account both separation distance and direction between values. Consider 2 values $z(x)$ and $z(x+h)$ at locations $x$ and $x+h$, respectively. Locations of these points can be designated in 1,2 , or 3 dimensions where $h$ is a vector with both distance and direction known as the "lag" between measured values. The variance per site is then represented by

$$
\mathbf{s}^{2}=[z(x)-m(z)]^{2}+[z(x+h)-m(z)]^{2},
$$

where $m(z)$ is the mean of the 2 values. The common mean in equation [1] can be factored out to show that $\mathrm{s}^{2}$ is half the square of the difference between $z(x)$ and $z(x+h)$ :

$$
s^{2}=[z(x)-z(x+h)]^{2} .
$$

Now, suppose $n$ pairs of observations are separated by the same lag, $h$; then the average variance is defined as

$$
s^{2}=\frac{1}{2 n} \sum_{i=1}^{n}\left[z\left(x_{i}\right)-z\left(x_{i}+h\right)\right]^{2},
$$

where $s^{2}$ is known as the semivariance of all measured values separated by the same lag $h$.

To proceed further, 2 assumptions concerning stationarity must be made. First, the expected value of $z$ at any location $x$ must be equal to the population mean $\mu$ :

$$
\mathrm{E}[\mathrm{z}(\mathrm{x})]=\mu .
$$

In other words, the sample mean must equal the population mean and must not change with location. Secondly, for any lag, $h$, the difference $[z(x)-z(z+h)]$ has a finite variance which also does not change with location. Therefore, the value of semivariance depends only on separation distance (lag) and direction, not location within the study area. These assumptions define what is known as the intrinsic hypothesis of regionalized variable theory (Webster 1985). If $h$ is limited to a maximum distance within which the intrinsic hypothesis is not violated, then any 2 observations $h$ apart will exhibit the same degree of difference.

Assuming the intrinsic hypothesis, Eq. [3] can now be generalized to define the semivariance as a function of $h$, the lag. This function is known as the semivariogram:

$$
\gamma(h)=\frac{1}{2 n} \sum_{i=1}^{n(h)}\left[z\left(x_{i}\right)-z\left(x_{i}+h\right)\right]^{2},
$$

where $\gamma(\mathrm{h})$ is the standard notation for semivariance as a function of $h$. The semivariogram simply describes how the variance of observations changes with separation distance in a given direction or it may be averaged over all directions.

The most common use of the semivariogram is in examining how properties vary in space; however, a lag can be defined with respect to any separation quantity. For example, geostatistical techniques can be applied over time to examine the temporal change in a selected property. The techniques could also be applied to examine how variability in animal grazing time changes with forage availability where forage availability is the separation quantity.

Once a semivariogram has been calculated using Eq. [5], a semivariogram model can be fit to the estimated semivariance values to help quantify the magnitude and range of spatial autocorrelation. Figure 1 shows the major features of a simple semivar-

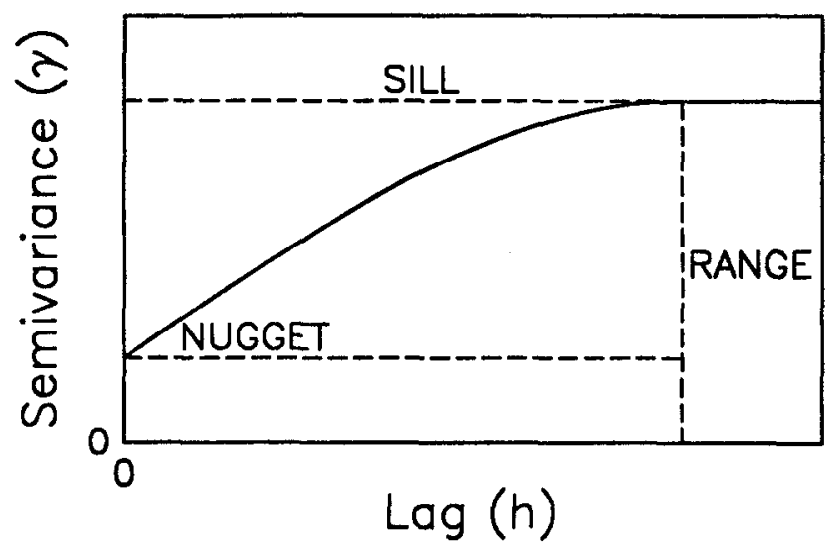

Fig. 1. Diagram of a spherical semivariogram model illustrating the interpretation of the terms "nugget," "sill" and "range."

iogram model. Most often, semivariance values increase with $h$ until they reach a maximum approximately equal to the sample variance of the measured variable known as the "sill." The lag at which the sill is reached is known as the "range" of the semivariogram. Beyond the range, values of the measured variable are no longer spatially correlated. If the semivariogram asymptotically approaches its maximum, then the range is arbitrarily chosen when $\gamma(\mathrm{h})$ is sufficiently close to the sill. Some semivariograms do not express a sill and appear to have an infinite variance. This can occur when the maximum sample separation distance is much smaller than the range of the semivariogram for that variable or when measured data is nonstationary. Semivariograms can also exhibit what is called "nested structure" when the semivariogram expresses more than 1 sill or range. Nested structure is observed when the spatial variation of a property is being influenced by 2 or more factors which are operating at different spatial scales.

By definition, at a lag of zero the semivariance is also zero. However, smooth curves fit to semivariograms often do not go through the origin. The variance associated with zero lag is called a "nugget variance," and the phenomenon is known as the "nugget effect." A nugget variance is the combination of variances associated with random variation, experimental error, and variation due to spatial autocorrelation with a range smaller than the minimum sampling interval.

Several simple functions are commonly used to model semivariograms. The functions used must be proven to be positive definite if estimation techniques, such as kriging, are to be used to insure that estimation variances are always positive or zero. Any combination of positive definite models can also be used to model nested structure within semivariograms. Oliver and Webster (1986) provide an excellent summary of valid models and their interpretations. 
The following functions from Oliver and Webster (1986) have been used alone or in combination to model semivariograms in this paper:

$$
\begin{gathered}
\gamma(\mathrm{h})=\mathrm{C}_{0}, \\
\gamma(\mathrm{h})=\mathrm{mh}, \\
\gamma(\mathrm{h})=\mathrm{C}_{1}\left[3(\mathrm{~h} / \mathrm{a})-(\mathrm{h} / \mathrm{a})^{3}\right] / 2 \quad \text { for } 0<\mathrm{h}<
\end{gathered}
$$

and

$$
\gamma(\mathrm{h})=\mathrm{C}_{1} \quad \text { for } \mathrm{b}>\mathrm{a},
$$

and

$$
\gamma(h)=u \cos (2 \pi h / w)+v \sin (2 \pi h / w) .
$$

Equation [6] represents a pure nugget model with a nugget variance of $\mathrm{C}_{0}$. Under this condition, classical statistics can be applied at all spatial intervals without fear of violating basic assumptions. Equation [7] is a linear model with slope $m$. Equation [8] is the expression for a spherical model with sill $C_{1}$ and range a. Equation [9] is the expression for a periodic model with cosine amplitude $u$, sine amplitude $v$, and wavelength $w$ (this model is only positive definite in 1 dimension). The amplitude of the periodic model can be calculated using the following expression:

$$
A=u \cos \left[\tan ^{-1}(v / u)+v \sin \left[\tan ^{-1}(v / u)\right]\right.
$$

(Mulla 1988).

In this paper, many semivariograms exhibited nested spatial structure consisting of spherical and periodic components or linear and periodic components. These semivariograms were modeled using linear combinations of equations [6], [8], and [9] or equations [6], [7], and [9], respectively. Values for the parameters in Eqs. [6], [7], [8], [9], and [10] were estimated using nonlinear least squares regression analysis with $n>125$ for all calculated values of semivariance.

\section{Results and Discussion}

\section{Classical Statistical Analysis}

Summary statistics for maximum and minimum soil temperatures measured at each depth along the 12.3-m transect on day 81 are given in Table 1. The Wilk-Shapiro statistic for each variable

Table 1. Descriptive statistics for maximum and minimum soil temperatures at 1-, 5-, and 10-em depths on day 81, 1989. The values for the Wilk-Shapiro statistic of normality (N) are also given for each variable and depth.

\begin{tabular}{lccccccc}
\hline \hline & \multicolumn{3}{c}{ Maximum temperature } & & \multicolumn{2}{c}{ Minimum temperature } \\
\cline { 2 - 4 } Statistic & $1-\mathrm{cm}$ & $5-\mathrm{cm}$ & $10-\mathrm{cm}$ & & $1-\mathrm{cm}$ & $5-\mathrm{cm}$ & $10-\mathrm{cm}$ \\
\hline Mean $\left(^{\circ} \mathrm{C}\right)$ & $14.3 \mathrm{a}$ & $11.7 \mathrm{~b}$ & $8.9 \mathrm{c}$ & $1.2 \mathrm{~d}$ & $2.0 \mathrm{e}$ & $2.9 \mathrm{f}$ \\
VAR $\left({ }^{\circ} \mathrm{C}\right)^{2}$ & 17.47 & 9.67 & 3.69 & 1.30 & 0.67 & 0.42 \\
$\mathrm{CV}$ & 29.2 & 26.6 & 21.6 & 95.0 & 41.0 & 22.4 \\
MIN $\left({ }^{\circ} \mathrm{C}\right)$ & 7.0 & 6.2 & 5.4 & -0.8 & 0.9 & 1.3 \\
MAX $\left({ }^{\circ} \mathrm{C}\right)$ & 22.8 & 17.3 & 11.8 & 3.2 & 3.5 & 4.0 \\
N & 0.97 & 0.94 & 0.94 & 0.96 & 0.93 & 0.98 \\
\hline
\end{tabular}

Mean values followed by different letters are significantly different at the $P<0.01$ level of probability.

showed that all measured values conformed to a normal distribution. The highest mean maximum and lowest mean minimum soil temperatures were found at the 1-cm depth compared to the 5- and 10-cm depths. The largest ranges in both minimum $\left(-0.8\right.$ to $\left.3.2^{\circ} \mathrm{C}\right)$ and maximum $\left(7.0\right.$ to $\left.22.8^{\circ} \mathrm{C}\right)$ temperatures were also found at the $1-\mathrm{cm}$ depth. These results indicate the presence of a large amount of spatial and temporal variability in soil temperature, particularly at the $1-\mathrm{cm}$ depth. Because many organisms develop at a rate governed by the amount of heat they absorb (Sharpe and DeMi- chele 1977, Wagner et al. 1984, Kemp and Sanchez 1987), soil temperature variations of this magnitude could significantly influence the site specific growth and development of a variety of biological organisms. An organism in a location with a maximum temperature of $23^{\circ} \mathrm{C}$ would likely develop and grow at a faster rate than an organism in a location with a maximum temperature of $7^{\circ}$ C. Large variations in soil temperature could also be important in the survival of emerging plants and insects.

Coefficients of variation (CV) were higher for minimum soil temperature than for maximum soil temperature at each measured soil depth (Table 1). CV values also showed a decrease in the variability of both minimum and maximum soil temperature with increasing depth. Values ranged from approximately $22 \%$ for maximum and minimum soil temperature at the $10-\mathrm{cm}$ depth to $95 \%$ for minimum soil temperature at the $1-\mathrm{cm}$ depth. The greater variability near the soil surface could have been caused by differences in micro-relief, shading from sagebrush and grass plants or from rocks exposed at the soil surface. The influence of these factors was then dampened in the lower soil depths. Davidoff et al. (1986) found that CV values for near surface soil temperatures along a bare soil transect varied from 6.8 to $4.4 \%$. They also found that the $\mathrm{CV}$ values decreased with an increase in depth.

Plots of maximum and minimum soil temperature at each depth along the 12.3-m transect on day 81 are shown in Figure 2. This

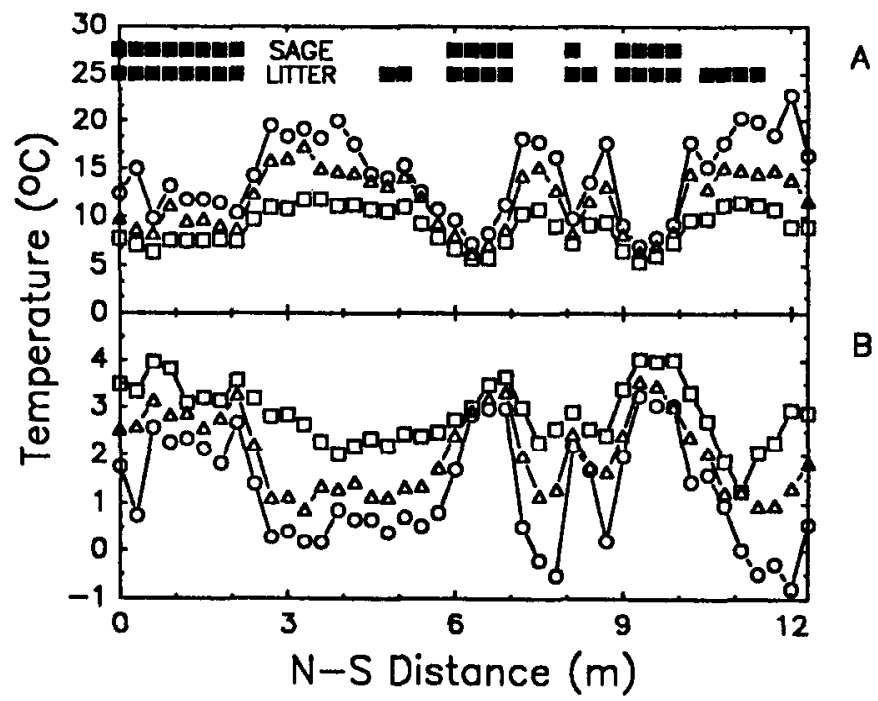

Fig. 2. Values of maximum (A) and minimum (B) soil temperatures for 1-(O), 5- $(\Delta)$ and 10-cm $(D)$ depths at 30-cm intervals along a 12.3-m north-south transect on day 81,1989 . the location of sagebrush plants and surface litter are also illustrated.

figure also displays the locations of sagebrush plants and soil litter along the transect (soil litter is defined as living or dead organic material from 0.5 to $5.0 \mathrm{~cm}$ in depth). These figures show the profound influence the sagebrush plants have on near surface soil temperatures. The plants produce periodic spatial patterns in both maximum and minimum soil temperature which are visible to a depth of $10 \mathrm{~cm}$. The sagebrush plants insulate the soil surface from incoming solar radiation during the day and from sensible heat loss during the night. Thus, the surface soils directly below sagebrush plants have significantly lower maximum and higher minimum temperatures compared to soils in the uninsulated interspace areas between sagebrush plants (Table 2).

Maximum and minimum soil temperatures at each depth were also negatively and positively correlated, respectively, with litter depth along the transect. However, the correlations were largely due to the fact that much of the surface litter in sagebrush-grass 
Table 2. Comparison of mean values for maximum and minimum soil temperatures $\left({ }^{\circ} C\right)$ at $1-, 5-$, and $10-\mathrm{cm}$ depths within sagebrush and interspace areas on day 81, 1989.

\begin{tabular}{lccccccc}
\hline \hline & \multicolumn{3}{l}{ Maximum temperature } & \multicolumn{3}{c}{ Minimum temperature } \\
\cline { 2 - 4 } \cline { 7 - 9 } Location & $1-\mathrm{cm}$ & $5-\mathrm{cm}$ & $10-\mathrm{cm}$ & & $1-\mathrm{cm}$ & $5-\mathrm{cm}$ & $10-\mathrm{cm}$ \\
\hline Sagebrush & $10.3 \mathrm{a}$ & $8.4 \mathrm{a}$ & $6.9 \mathrm{a}$ & & $2.4 \mathrm{a}$ & $2.9 \mathrm{a}$ & $3.5 \mathrm{a}$ \\
Interspce & $17.0 \mathrm{~b}$ & $13.9 \mathrm{~b}$ & $10.3 \mathrm{~b}$ & & $0.5 \mathrm{~b}$ & $1.4 \mathrm{~b}$ & $2.5 \mathrm{~b}$ \\
\hline
\end{tabular}

Mean values in the same column followed by different letters are significantly different at the $P<0.01$ level of probability.

plant communities is found directly beneath sagebrush plants. Therefore, the influence of surface litter on soil temperature was examined separately within sagebrush and interspace areas.

An analysis of variance showed that litter (mostly small grass crowns and moss clumps) in the interspace areas had little influence on near surface soil temperatures. This may have been due to the small size (approximately 3 to $6 \mathrm{~cm}$ in diameter) of the grass crowns and moss clumps on the site. Heat could easily move in from or be lost to the surrounding uninsulated soil, thus, controlling the soil temperature beneath the insulated areas.

The influence of litter (mostly sagebrush litter and moss) depth on soil temperature under sagebrush plants was examined using linear regression analysis. Significant linear correlations $(p=0.05)$ were found between maximum soil temperatures at the $1-, 5-$, and 10-cm depths and litter depth and under the sagebrush plants with r-values of $0.75,0.58$ and 0.49 , respectively. These results are due to the greater litter depth found on the north side of the plants, which is an indirect effect of the variable shading of the sagebrush plants. Sunlight is able to reach the soil on the south side of the plant, which raises the soil temperature and makes the site more aridic and less productive than the cooler north side of the plant. Minimum soil temperature was only significantly correlated to litter depth $(p=0.05, r=0.53)$ at the $1-\mathrm{cm}$ depth because of the more uniform insulating effect of the sagebrush against longwave radiation losses during the night.

\section{Geostatistical Analysis}

\section{Spatial Patterns}

Geostatistics were used to further quantify the observed periodic spatial patterns in soil temperature produced by sagebrush plants. Additionally, we were interested in examining the influence of sagebrush on the magnitude and pattern of diurnal fluctuations in near-surface soil temperature.

Semivariograms were calculated for daily maximum and minimum soil temperature from each of 1-, 5-, and 10-cm soil depths for days 81 to 86, 1989. Data values from a 6-day period were used both to determine if spatial patterns in soil temperature were consistent over time and to increase the number of values used in calculating each value of semivariance. Values of semivariance and the best fitting semivariogram models for maximum and minimum soil temperatures at each soil depth are shown in Figure 3. Model parameter values for the best fitting semivariogram models are given in Table 3 . Sill values for the spherical component semivariogram models for each variable and depth showed that maximum soil temperature had a greater magnitude of spatial variability compared to minimum soil temperature and that the magnitude of variation decreased with depth for each variable. These results were similar to sample variance patterns for maximum and minimum soil temperatures on day 81 reported in the classical analysis section of this paper.

Figure 3 illustrates that sinusoidal periodicities in spatial variability of soil temperature existed to a depth of $10 \mathrm{~cm}$. The amplitude of the periodic semivariograms component model (A) was much larger for maximum soil temperature than for minimum soil
Table 3. Values for the nugget $\left(C_{0}\right)$, sill $\left(C_{1}\right)$, range (a), cosine amplitude (u), wavelength $(w)$ and sine amplitude $(v)$ parameters found in he semivariogram models of Eqs. [6], [8], and [9] for maximum and minimum soil temperature at 1-, 5-, and 10-cm depths along the 12.3-m n-s transect on days 81-86, 1989 (shown in Fig. 3). Values for the amplitude of the periodic semivariogram component model (A) are also given for each variable and depth.

\begin{tabular}{ccccccc}
\hline \hline $\mathrm{C}_{0}$ & $\mathrm{C}_{1}$ & a & u & w & v & A \\
\hline$\left({ }^{\circ} \mathrm{C}\right)^{2}$ & $\left({ }^{\circ} \mathrm{C}\right)^{2}$ & $(\mathrm{~m})$ & $\left({ }^{\circ} \mathrm{C}\right)$ & $(\mathrm{m})$ & $\left({ }^{\circ} \mathrm{C}\right)^{2}$ & $\left({ }^{\circ} \mathrm{C}\right)^{2}$
\end{tabular}

Maximum

Temperature

$\begin{array}{rlrrrrrr}1 \mathrm{~cm} & 3.98 & 14.04 & 1.14 & -1.440 & 3.32 & -3.42 & 3.78 \\ 5 \mathrm{~cm} & 0.0 & 8.22 & 1.58 & 0.370 & 2.84 & -0.64 & 0.74 \\ 10 \mathrm{~cm} & 0.0 & 3.62 & 2.08 & 0.068 & 2.62 & -0.20 & 0.21\end{array}$

Minimum

Temperature

\begin{tabular}{rlllllll}
$1 \mathrm{~cm}$ & 0.22 & 0.79 & 0.97 & -0.140 & 3.28 & -0.10 & 0.17 \\
$5 \mathrm{~cm}$ & 0.059 & 0.49 & 1.45 & -0.032 & 2.76 & -0.064 & 0.072 \\
$10 \mathrm{~cm}$ & 0.0 & 0.34 & 1.56 & -0.059 & 3.05 & 0.041 & 0.072 \\
\hline
\end{tabular}

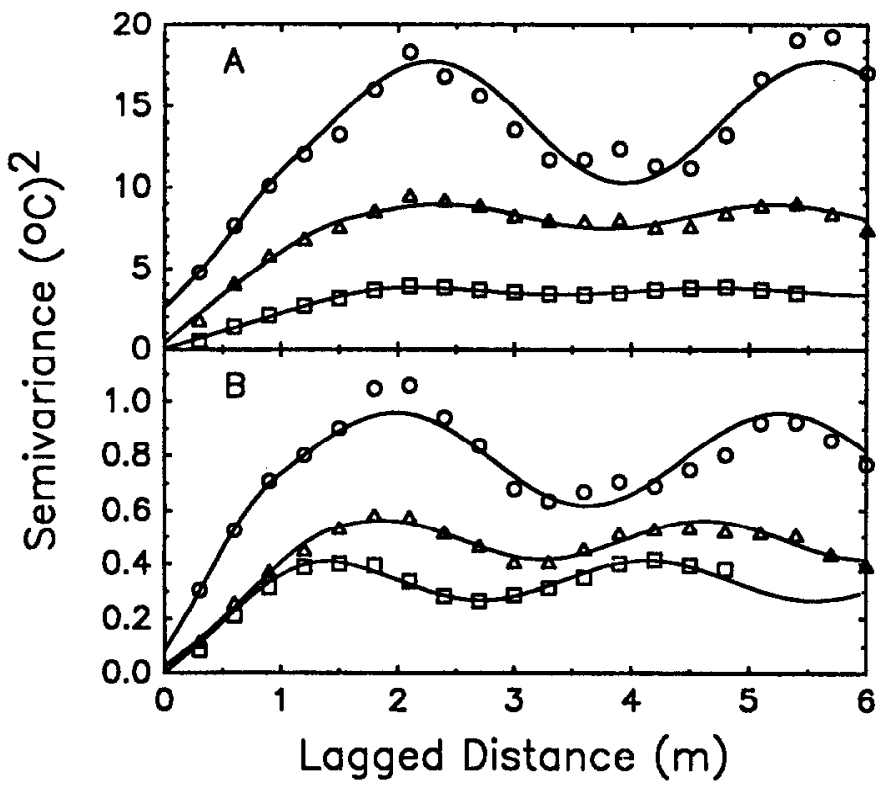

Fig. 3. Values of semivariance and the best-fitting semivariogram models for maximum (A) and minimum (B) soil temperatures for 1-(0), 5- ( $\Delta$ ) and $10-\mathrm{cm}(\square)$ depths at $30-\mathrm{cm}$ intervals along $\$ 12.3-\mathrm{m}$ north-south transect on days 81 to $86,1989$.

temperatures at all measured depths (Table 3 ). This is complementary to the larger spread in maximum soil temperature compared to minimum soil temperature found for each depth in the previous section. These results indicate that the spatial variability in soil temperature was greater for maximum soil temperature than for minimum soil temperature. Thus, the amount of shade produced by sagebrush may have a greater impact on organism growth and development than the degree of thermal insulation sagebrush plants provide against sensible heat loss during the night. In addition, during much of the year, the amount of shaded area produced by shadowing from sagebrush plants far exceeds the percent aerial cover that the plants provide. Therefore, the percent ground surface insulated from incoming solar radiation is greater than the percent ground surface insulated against sensible heat loss.

The precise estimation of the range (a) of the spherical semivariogram component model is confounded by the periodicity exhi- 
bited in many of the semivariograms. An approximate value of the true range of spatial variability for each variable is the distance associated with the first peak in the semivariograms which ranged between 1.0 and $2.1 \mathrm{~m}$ between variables. The wavelength of the periodic semivariogram component $(w)$ for each variable and depth range between 2.6 and $3.3 \mathrm{~m}$. These results indicate that the periodic spatial distribution patterns in soil temperature at each soil depth within this sagebrush-grassland plant community occurred on average in cycles approximately $3 \mathrm{~m}$ in length. The average distance between sagebrush plants was also near $3 \mathrm{~m}$ as shown in Figure 2. This suggests that spatial variability in soil temperature within this plant community is related to the spatial distribution pattern of sagebrush plants.

Results also indicate that during sampling, heat transport down through the soil profile during the day was dampened more than heat transport up and out the top of the profile during the night (Fig. 3 and Table 3). Amplitudes of the periodicities in maximum and minimum temperature at the $10-\mathrm{cm}$ depth were 6 and $42 \%$ of the amplitudes at the 1-cm depth, respectively. High levels of incoming solar radiation were received for only short time periods during the middle of each day, while sensible heat losses were more uniform throughout each night. This produced sharp peaks in maximum temperature and smooth broad valleys in minimum temperature near the soil surface (Fig. 4). Higher temperature

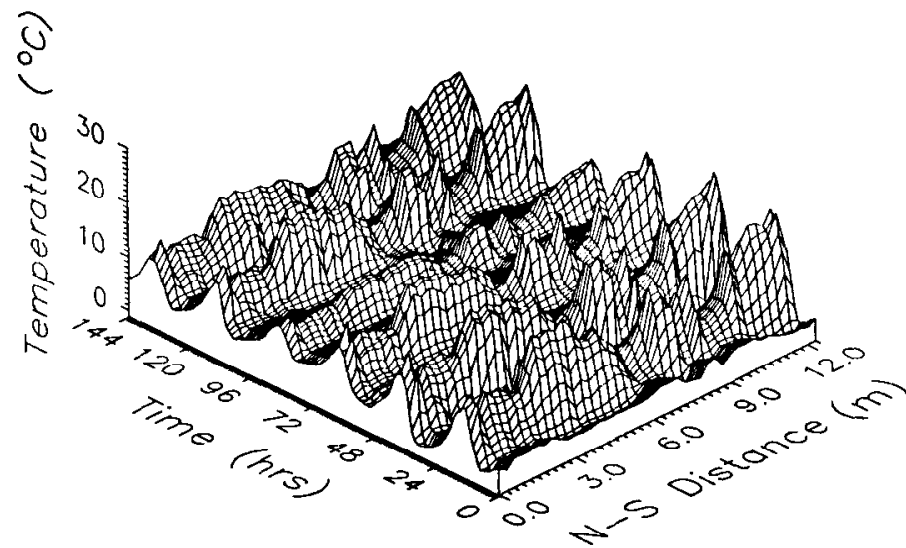

Fig. 4. Values of hourly soil temperature measured at the $1-\mathrm{cm}$ depth on 30 -cm intervals along $12.3-\mathrm{m}$ north-south transect for days 81 to 86 , 1989.

gradients for movement of heat downward into the soil existed for much shorter time periods compared to the lower temperature gradients for movement of heat upward toward the soil surface. The net result was that the amount of heat transported downward exceeded the amount of heat transported upward due to very high surface temperatures during the day; thus, the lower soil layers were accumulating heat and warming up (Fig. 4).

\section{Temporal Patterns}

Geostatistical techniques were also used to examine differences in the magnitude and structure of temporal variability in soil temperature between sagebrush and bare interspace areas. Figure 4 is a plot of hourly soil temperature values for the 1-cm depth over a 144-hr period from day 81 through day 86,1989 . It shows the magnitude of temporal variation in soil temperature along the transect as well as the influence of the sagebrush plants on the spatial and temporal variablity of soil temperature over the entire 6-day period. Sagebrush plants were located between 0 to 2, 6 to 7 , 8 to 8.5 , and 9 to $10 \mathrm{~cm}$ along the transect.

Semivariograms were calculated using hourly soil temperature values from each depth under both sagebrush and interspace areas. The values of semivariance and the best-fitting semivariogram models for soil temperature at each depth under sagebrush and

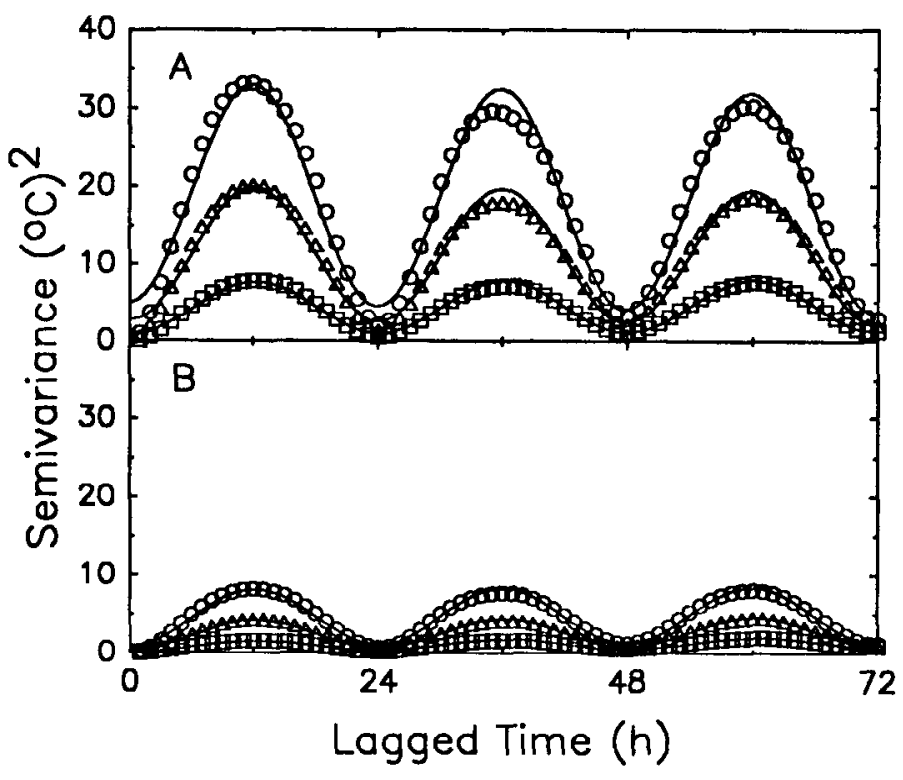

Fig. 5. Values of semivariance and the best fitting semivariogram models for hourly soil temperature under bare interspace (A) and sagebrush (B) areas on days 81 to 86,1989 . Data is given for the $1-(0), 5-(\Delta)$ and $10-\mathrm{cm}$ $(\square)$ soil depths under each area.

and interspace are shown in Figure 5. Nugget values $\left(C_{0}\right)$ of the linear semivariogram component models given in Table 4 represent the Y-intercepts of straight lines fitted through the values of semivariance for each variable and depth. Slopes (m) of the lines for each variable were quite small; thus, $C_{0}$ values are representative of the sample variance for each variable and depth. Like spatial variability, temporal variability was also greater for interspace areas compared to sagebrush areas, and the variability decreased with depth. Comparison of $C_{1}$ values in Table 3 and $C_{0}$ values in Table 4 showed that temporal variability in soil temperature was greater than the spatial variability for both maximum or minimum

Table 4. Values for the $Y$-intercept $\left(\mathrm{C}_{0}\right)$, slope (m), cosine amplitude (u), wavelength ( $w$ ) and sine amplitude (v) parameters found in the semivariogram models of Eqs. [6], [7], and [9] used to model the temporal variability in soil temperature at 1-, 5-, and 10-cm depths under sagebrush and interspace areas for days 81-86, 1989 (shown in Fig. 5). Values for the amplitude of the periodic semivariogram component model (A) are also given for each variable and depth.

\begin{tabular}{ccccccc}
\hline & $\mathrm{C}_{0}$ & $\mathrm{~m}$ & $\mathrm{u}$ & $\mathrm{w}$ & $\mathrm{v}$ & $\mathrm{A}$ \\
\hline & $\left({ }^{\circ} \mathrm{C}\right)^{2}$ & $\left.\left({ }^{\circ} \mathrm{C}\right)^{2} / \mathrm{hr}\right)$ & $\left({ }^{\circ} \mathrm{C}\right)^{2}$ & $(\mathrm{hr})$ & $\left({ }^{\circ} \mathrm{C}\right)^{2}$ & $\left({ }^{\circ} \mathrm{C}\right)^{2}$ \\
Sagebrush & & & & & & \\
$1 \mathrm{~cm}$ & 4.48 & 0.0067 & -3.50 & 23.89 & -0.12 & 3.50 \\
$5 \mathrm{~cm}$ & 2.23 & 0.0094 & -1.83 & 23.99 & -8.11 & 1.83 \\
$10 \mathrm{~cm}$ & 0.72 & 0.011 & -0.68 & 24.09 & -0.0016 & 0.68 \\
Interspace & & & & & & \\
$1 \mathrm{~cm}$ & 19.13 & -0.022 & -14.12 & 23.93 & 0.18 & 14.12 \\
$5 \mathrm{~cm}$ & 11.35 & -0.0081 & -8.60 & 23.91 & -0.15 & 8.60 \\
$10 \mathrm{~cm}$ & 4.23 & 0.0049 & -3.36 & 23.91 & -0.12 & 3.37 \\
\hline
\end{tabular}

temperatures at the same depth. In addition, the amplitude of temporal variability was also greater than the amplitude of spatial variability for minimum and maximum soil temperatures at all depths.

The semivariograms in Figure 5 show distinct sinusoidal diurnal patterns over time for each location and depth, with a common periodic wavelength (w) of approximately $24 \mathrm{hr}$ (Table 4). At each depth, the amplitude of the diurnal periodic pattern was much 
larger for interspace areas compared to areas covered with sagebrush plants. The amplitude of temporal variability in soil temperature under sagebrush ranged from 15 to $25 \%$ of the size of the amplitude of temporal variability found for soils in interspace areas at each measured depth. Amplitude of the temporal variability in soil temperature at the 10-cm depth in the interspace was approximately equal to the amplitude of the temporal variability in soil temperature under sagebrush at the $1-\mathrm{cm}$ depth. Thus, sagebrush and associated surface litter insulate and dampen diurnal fluctuations in near surface soil temperature equivalent to the dampening effect of $10 \mathrm{~cm}$ of soil. Sagebrush also sufficiently insulate the soil so only small diurnal fluctuations in soil temperature exist at the $10-\mathrm{cm}$ depth.

\section{Conclusions}

The insulating effect of sagebrush plants produced significant periodic spatial patterns in soil temperature across the landscape. Bare interspace areas had higher maximum and lower minimum soil temperatures at depths up to $10 \mathrm{~cm}$ compared to areas under sagebrush plants. The presence of small plants such as grass clumps and moss seem to have little influence on near surface soil temperatures compared to the larger sagebrush plants.

Sagebrush plants also influenced the spatial variability of diurnal oscillations in soil temperature. Diurnal variations in soil temperature were found to be greatest in bare interspace areas and were greater than measured spatial variations in maximum and minimum soil temperature.

When trying to simulate the soil micro-climate, whether it be for predicting range revegetation success or estimating insect populations, the spatial and temporal variation of the soil micro-climate must be considered. The magnitude of both spatial and temporal variations in soil temperature found at this site are large enough to strongly influence the establishment and survival of organisms that inhabit the near-surface soil environment. In this case, making the assumption that the soil micro-climate is consistent over time and space would lead to very large simulation errors. The geostatistical analysis presented here showed that soil temperature had a range of spatial autocorrelation of approximately $1-2 \mathrm{~m}$ and that the pattern was cyclic in nature with a periodicity of around $3 \mathrm{~m}$ in length. A model simulation of soil temperature for a single point on the landscape would only spatially represent an area of less than 1-3 $\mathrm{m}$ in radius around the modeled point. The actual size of the area represented by the model simulation would be determined by the amount of simulation error the model would be willing to accept. Fortunately, on this site the spatial patterns in soil temperature are periodic in structure, which allows the accuracy of simulation to be significantly improved by dividing the landscape into 2 distinct areas, sagebrush and interspace, each of which could be modeled separately and would represent a certain percentage of the landscape.

Additional descriptive information on the spatial and temporal variability of soil and climatic variables needs to be obtained and incorporated into future modeling and range restoration efforts. We present results describing the spatial and temoral variability of soil micro-climatic conditions within only 1 sagebrush/grass plant community. More information on the spatial and temporal variability of additional soil and climatic variables within other major rangeland plant communities is also needed to determine the magnitude and structure of the variability that exists and the causative factors involved.

The geostatistical procedures presented in this paper are useful tools that can be used in many creative and productive ways to improve our ability to manage range resources and make quality land management decisions. Geostatistics were used here to help quantify spatial and temporal patterns in soil temperature that were qualitatively obvious; however, the techniques are even more useful for exploring and quantifying patterns of variability in other factors which are much less obvious and may go undetected under most standard classical statistical analyses. These and other geostatistical techniques are quite applicable and useful in the analysis of many types of data in range science and should be considered in future studies of rangeland resources.

\section{Literature Cited}

Achouri, M., and G.F. Gifford. 1984. Spatial and seasonal variability of field measured infiltration rates on a rangeland site in Utah. J. Range Manage. 37:451-455.

Burgess, T.M., and R. Webster. 1980. Optimal interpolation and isarithmic mapping of soil properties: 1 . The semivariogram and punctual krigin. $J$. Soil Sci. 31:315-331.

Davidoff, B., J.W. Lewis, and H.M. Selim. 1986. Variability of soil temperature with depth along a transect. Soil Sci. 142:114-123.

Davidoff, B., and H.M. Selim. 1988. Correlation between spatially variable soil moisture content and soil temperature. Soil Sci. 145:1-10.

Evans, R.A., B.L. Kay, and J.A. Young. 1975. Microenvironment of a dynamic annual community in relation to range improvement. Hilgardia 43:79-102.

Folorunso, O.A., and D.E. Rolston. 1984. Spatial variability of field measured denitrification gas fluxes. Soil Sci. Soc. Amer. J. 48:1214-1219.

Gajem, Y.M., A.W. Warrick, and D.E. Meyers. 1981. Spatial dependence of physical properties of a typic Torrifluvent soil. Soil Sci. Soc. Amer. J. 46:709-715.

Hatfield, J.L., J.P. Millard, and R.C. Goettelman. 1982. Variability of surface temperature in agricultural fields of central California. Photogrammetric Engineering and Remote Sensing. 8:1319-1325.

Hatfield, J.L., M. Vauclin, S.R. Vieira, and R. Bernard. 1984. Surface temperature variability patterns within irrigated fields. Agr. Water Manage. 8:429-437.

Isanks, E.H., and R.M. Srivastava. 1989. An introduction to applied geostatistics. Oxford University Press Inc., New York, N.Y.

Journel, A.G., and C.J. Huijbregts. 1978. Mining geostatistics. Academic Press, New York, N.Y.

Kemp, W.P., and N.E. Sanchez. 1987. Differences in post-diapause thermal requirements for eggs of two rangeland grasshoppers. Can. Ent. 119:653-661.

Merzougui, M., and G.F. Gifford. 1987. Spatial variability of infiltration rates on a semiarid seeded rangeland. Hydrolog. Sci. J. 32:243-250.

Mulla, D.J. 1988. Using geostatistics and spectral analysis to study spatial patterns in the topography of southeastern Washington State. Earth Surface Processes and Landforms 13:389-405.

Naney, J.W., R.D. Williams, and L.R. Ahuja. 1988. Variability of soil water properties and crop yield in a sloped watershed. Water Resour. Res. 24:281-288.

Oliver, M.A., and R. Webster. 1986. Semi-variograms for modelling the spatial pattern of landform and soil properties. Earth Surface Processes and Landforms. 11:491-504.

Russo, D., and E. Bresler. 1981. Soil hydraulic properties as stochastic Processes: 1. An Analysis of field scale variability. Soil Sci. Soc. Amer. J. 45:682-687.

Shapiro, S.S., and R.S. Francia. 1972. An approximate analysis of variance test for normality. J. Amer. Stat. Assoc. 67:216-216.

Sharpe, P.J.H., and D.W. DeMichele. 1977. Reaction kinetics of poikilotherm development. J. Theor. Biol. 64:649-670.

Sisson, J.B., and P.J. Wierenga. 1981. Spatial variability of steady-state infiltration rates as a stochastic process. Soil Sci. Soc. Amer. J. 45:699-704.

Steel, R.G.D., and J.H. Torrie. 1980. Principles and procedures of statistics. McGraw-Hill Book Co. Inc. New York, N.Y.

Stephenson, G.R. 1977. Soil, geology, and vegetation inventories on the Reynolds Creek Experimental Watershed, Boise, ID. Agricultural Experiment Station, Univ. Idaho Coll. Agr., Moscow.

Vauclin, M., S.R. Vieira, R. Bernard, and J.L. Hatfield. 1982. Spatial variability of surface temperature along two transects of a bare soil. Water Resour. Res. 18:1677-1686.

Vieira, S.R., J.L. Hatfield, D.R. Nielson, and J.W. Biggar. 1983. Geostatistical theory and application to variability of some agronomic properties. Hilgardia. 51:1-75. 
Wagner, T.L., H. Wu, P.J.H. Sharpe, R.M. Schoolfield, and R.N. Coulson. 1984. Modeling insect development rates: $A$ literature review and application of a biophysical model. Ann. Entomol. Soc. Amer. 77:208-225.

Webster, R. 1985. Quantitative spatial analysis of soil in the field. In: Advances in soil science. B.A. Steward (ed). Springer-Verlag, New York, N.Y.

Webster, R., and S. Nortcliff. 1984. Improved estimationat of micronutrients in hectare plots of the Sonning series. J. Soil Sci. 35:667-672.
Williams, R.D., L.R. Ahuja, J.W. Naney, J.D. Ross, and B.B. Barnes. 1987. Spatial trends and variability of soil properties and crop yield in a small watershed. Trans ASAE. 30:1653-1660.

Yates, S.R., and A.W. Warrick. 1987. Estimating soil water content using cokriging. Soil Sci. Soc. Amer. J. 51:23-30.

Yost, R.S., G. Uehara, and R.L. Fox. 1982. Geostatistical analysis of soil chemical properties of large land areas: 1. Semivariograms. Soil Sci. Soc. Amer. J. 46:1028-1032. 